\title{
ИСТОРИЯ ОБРАЗОВАНИЯ И НАУЧНЫХ ИССЛЕДОВАНИЙ В БРАЗИЛИИ
}

\section{ОРИГИНАЛ СТАТЬИ}

FREITAS, Roberto Araujo de Moraes ${ }^{1}$

MARTINS, Priscila Bernardo ${ }^{2}$

FREITAS, Roberto Araujo de Moraes. MARTINS, Priscila Bernardo. История образования и научных исследований в Бразилии. Revista Científica Multidisciplinar Núcleo do Conhecimento. 04 год, Эд. 12, Vol. 08, стр. 127-138. Декабрь 2019 года. ISSN: 2448-0959, ссылка для доступа: https://www.nucleodoconhecimento.com.br/образование-ru/историяобразования

\section{PEЗЮME}

В настоящей статье рассматриваются исторические преобразования преподавательской деятельности в Бразилии, а также ее участие в научнонаучных исследованиях, учитывая влияние, возникающее от унаследованных религий из Европы, до отличительных признаков ресурсов технологии в руках отечественных пользователей. Этот момент отмечен переходом между 20-м и 21-м веками, тем самым представляя собой безудержную революцию в

1 Аспирант в области преподавания в высших учебных заведениях, окончил фракультет вычислительной техники.

2 Докторская степень в прогрессе в области преподавания науки. Степень магистра в области преподавания естественных наук. Специализация в дистанционном образовании: подготовка материалов, репетиторство и виртуальная среда. Специализация в бизнес-педагогии. Выпускной в прогресс в математике. Выпускной в области управления людскими ресурсами. Выпускной в Педагогии. 
технологическом секторе, основным инструментом коммуникации и исследований, что привело к длительному процессу адаптации. Необходимо отметить трудности, что в процессе изоляции знаний о своей местной культуре, мнения и опыт его собственной и академический багаж, с которым учитель должен передать в студенческое тело, потому что он должен понимать, что Бразилия фриксирует влияние различных народов во всем мире, что заставило нас иметь такую смешанную культуру. В разгар стольких исторических преобразований, преподавательская деятельность должна постоянно перерабатываться. По этой причине эта работа становится все более трудной, поскольку учитель страдает от воздействия сети на мир, так как это отражается на производительности и надежности результатов литературных и научных работ. Это навсегда поставит под угрозу взаимосвязь между знаниями и информацией.

Ключевые слова: Технологии, исследования, образование, надежность.

\section{1. ВВЕДЕНИЕ}

Осуществление преподавания всегда претерпевало социальные изменения, особенно в соответствии с идеологическими интересами каждого региона, либо в зависимости от религиозного, либо политического характера. Из истории Бразилии, начиная с 1500 года, влияние христианства в первых школах страны, организованных европейским учреждением под названием companhia де Иисус, имеет отношение. На протяжении многих лет наблюдались периоды стимулирования, а также пренебрежение к уровню образования населения. Этот разрыв является реальностью, которая до сих пор не преодолена, главным образом потому, что можно придать очень низкие инвестиции в академический сектор, а также в научные исследования, даже если есть законы, которые поддерживают этот сектор, в некотором роде.

Закон, который родился в Бразилии империи, в частности, в правительстве Д. Педро І. Вышеупомянутый был назван Законом руководящих принципов и баз, 
закон, который претерпевает, по сей день, изменения во всех правительствах, будучи его последней версии от 1996 года. Образовательный традиционализм, приданный библиотеками, книгами, статьями, редакционными статьями и т.д., начинает трансформироваться в конце 20-го века с агломерцией информации в Интернете. Это находит свое отражение в трудностях, с которыми учителя и исследователи до настоящего времени приспосабливаются к новым тенденциям работы, поскольку в той же степени, что они облегчают доступ к информации, резко снижают надежность контента.

\section{2. ИСТОРИЯ ОБРАЗОВАНИЯ И НАУЧНЫХ ИССЛЕДОВАНИЙ В БРАЗИЛИИ}

\section{1 ОТКРЫТИЕ И КОЛОНИЗАЦИЯ}

Первые значительные показатели показателей бразильского образования, в научно-школьном смысле, параллельны истории страны, с ее открытием правительством Португалии, официально в 1500 году. Поскольку всегда, доступ к информации и то, как люди создаются и образованы в Бразилии имеют последствия от того, как общество ведет себя, потому что он манипулируется в соответствии с желанием правящего класса. По словам Рибейро (1993 год), поселенцам неинтересно разрешать доступ к информации коренным жителям, поскольку это стратегия, способная выскакивать шок различных культур и интересов между судом и коренным населением.

Априорное предложение заключалось в том, чтобы заставить людей из местной массы слепо и покорно сотрудничать с этой работой, и эта цель была разработана европейцами на основе искажения культурной и религиозной самобытности коренного бразильского населения. По этой причине они едва имели доступ к грамотности, и поэтому их культура была насильственно подделана. В ходе этого процесса несколько коренных народов были уничтожены за то, что они не подчинились суду над иезуитским судом. Из Европы поселенцы имели поддержку иезуитов для распространения христианства в

Disponível em: https://www.nucleodoconhecimento.com.br/образование-ru/история- 
Бразилии, как они делали в нескольких странах через их родительского учреждения, Общество Иисуса. Организация возвела несколько основных учебных заведений в Бразилии.

Двадцать один год после прибытия иезуитов, Орден Общества Иисуса уже может иметь пять начальных школ, в различных местах по всей стране, особенно в прибрежных районах: Порто Сегуро, Ильхеус, Эспириту-Санту, Сан-Висенте и Сан-Паулу Пиратина. С ними три школы: Сальвадор, Рио-де- Здесь разница между школой и школой происходит в зависимости от уровня образования. Поэтому читайте школу для начальных учебных заведений (Первый класс или начальная школа I и II, в соответствии с номенклатурой Idb/96) и средние учебные заведения (Вторая степень или средняя школа, в соответствии с номенклатурой, установленной LDB/96).

Иезуиты отвечали за образование в Бразилии в течение примерно двухсот лет. Во-первых, катехизация индейцев, которых они называли дикарями. Позже они основали школы и миссии. Этот процесс распространения западных учений следовал до изгнания иезуитов в 1759 году. При этом образовательный процесс вступил в период застоя. По словам Розы (2014), Орден Иисуса снизилась после примерно 200 лет прибытия португальцев в Бразилию. В то время, Себастьян Хосе де Карвалью электронной Мело, маркиз Помбал, был главой государства и международным дипломатом Португалии.

Была даже попытка в 1823 составляющих, в соответствии с NISKIER (1969) в связи с провозглашением независимости, чтобы увеличить систему образования, через статью 250, которая определила создание начальных школ в каждой деревне, гимназии в каждом районе и университетов в некоторых местах, но это было только в теории, потому что император распустил учредительи и в следующем году он дал первую Конституцию империи и в статье 179 сказал: "начальное образование является бесплатным для всех граждан". В 1827 году он принял Общий закон, который будет 
первым и единственным для начального государственного образования до 1946 года. Д. Педро II, хотя он считается очень культовой правит уже 49 лет, но его проекты в образовательном секторе были робкими и безрелевантными (ALVES, 2009, стр. 10).

Как член португальской элиты, он очень беспокоил его о подъеме религиозной социальной области Ордена, так как он разбалансировал политические полномочия правительства. В результате 22 января 1759 года было опубликовано предложение, определяющее освобождение и денатурацию иезуитов с территории Португалии (включая Бразилию). Ситуация изменилась только с приходом королевской семьи. В период монархии, образование чувствует отражение изгнания иезуитов. Дон Педро я правил в течение многих лет, но не имеет новостей.

\section{2 СОЦИАЛЬНЫЕ ИНВЕСТИЦИИ В СЕКТОРЕ ОБРАЗОВАНИЕ И ВЛИЯНИЕ ПРОФЕССОРА ПАУЛО ФРЕЙРЕ}

Из-за длительного периода, что Общий закон длился, сектор образования в Бразилии только претерпел значительные преобразования с 1946 года, после осаждения Гетелио Варгас, В период, который стал известен как Вторая Республика: когда диктатура Варгас подошел к концу, и бразильский республиканский режим был возобновлен. В 1948 году, в соответствии с тем, что было определено пятой конституцией, началась работа над Законом Руководящих принципов и баз, который был обнародован в 1961 году. Одновременно с обнародованием LDB, профрессор Пауло Фрейре в народном образовании метод появился. Движение народной культуры, МСР, управляемый Паулу Фрейре себя, были фермеры, как первые студенты, чтобы пройти через этот опыт, будучи грамотным изнутри, через свою собственную работу. Полученные результаты - 300 грамотных работников за 45 дней - глубоко ели общественное мнение. 
Было принято решение применить этот метод на всей территории страны, но на этот раз он был поддержан федеральным правительством. С момента принятия LDB наблюдается значительный рост инвестиций в образование. Популяризация методов преподавания профессора Пауло Фрейре вдохновила несколько людей и учреждений, создав тем самым новые проекты и социальные группы для поддержки распространения профессиональной подготовки и знаний. Natal/RN был первым бразильским городом, который применил эту дидактику с кампанией по борьбе с грамотностью "Standing On The Ground also Learns To Read", направленной на неграмотных взрослых. Алвес (2009, стр. 67) говорит, что есть также в то время "Народные центры культуры, связанные с Национальным союзом студентов; Движение за массовое образование (связанное с Национальной конференцией епископов Бразилии) и правительством Союза".

В 1962 году в соответствии со статьей 9 Закона о руководящих принципах и базах был создан Федеральный совет по образованию. Это происходит вместо Национального совета по образованию. В том же году по предложению метода Паулу Фрейре были созданы Государственные советы по вопросам образования, Национальный план в области образования и Национальная программа по ликвидации неграмотности, причем два последних были созданы министерством образования и культуры. С созданием этой системы, Фрейре открывает новый этап в области образования для взрослых в Бразилии. Этот образовательный проект, осуществляемый Службой культурного расширения Университета Ресифи под его руководством под названием "Система образования Паулу Фрейре", был главной мишенью для неграмотности взрослых. Однако после короткого времени осуществления эти проекты были прерваны военным переворотом 1964 года. Таким образом, по словам Оливейры (2001, стр.56):

До 31 марта 1964 года отношения между прогрессивными правительствами и народными движениями, ориентированными на народное образование, были совместными. То есть для того, чтобы приложить усилия для реализации предложений бразильского 
популизма и развития. Некоторые из самых выразительных движений образования и массовой культуры в Бразилии рождаются там. Это выражения этого движения: Движение народной культуры (МПП), Движение за массовое образование (МЭБ), Популярный центр культуры (КПК), а также кампания «Стоять на земле» также научилась читать». С тех пор образование и культура перестали быть обусловлены простым формированием электората. Инструменты трансформации социальной структуры рассматриваются как пространства для формирования сознательных, критических и участников существ.

После военного переворота в 1964 году, сильные репрессии падает на общественные движения, также встает на себя группи и учреждения, которые работали на популярном образовании и культурных проектов. МЭБ, однако, попрежнему действует из Национальной программы грамотности. В период с 1970 по 1971 год, когда Бразилия, когда была учреждена институциональная группа No 05 в правительстве Коста-Силвы, вступила в самый репрессивный период военной диктатуры, период, называемый "переворотом в рамках переворота". В этот период правительство решило установить еще более крупную структуру, бразильское движение грамотности - MOBRAL (Закон № 5.379 de 15/12/67).

Среди его целей было распространение официальной идеологии развития в целях укрепления нынешней модели господства и модернизации. Однако, по словам Биттара и Биттара (2012, стр. 163), правительства после диктатуры также не смогли решить эту проблему и, кроме того, «за несоблюдение универсализации базовой школы, что было выполнено большинством стран Переход от 19-го до 20-го века, Бразилия вступила в 21-м веке с этим позорным наследием ". 


\section{3 НАУЧНО-ИССЛЕДОВАТЕЛЬСКИЕ СТИМУЛИРУЮЩИЕ УЧРЕЖДЕНИЯ}

Также в начале 1960-х годов часть правительства увидела преимущество в инвестировании в технологическое и научное развитие. В течение этого периода, Fapesp - Сан-Паулу государственный фонд поддержки научных исследований был создан, а вместе с ним несколько других связанных учреждений Бразилии в. Среди целей было создание strictu sensu модели выпускников. Следует также отметить SBPC - Бразильское общество за прогресс науки, созданное в 1934 году в городе Сан-Паулу / SP, но которое начало иметь больше видимости и автономии в переходный период между 1960-х и 1970-х годов. В 1988 году Бразилия обнародовала свою новую конституцию, известную как Конституция граждан, в статье 208 которой устанавливается, что государство обязано гарантировать обязательную и бесплатную начальную школу.

[...] это является важной исторической вехой в бразильском образовании, поскольку этот закон реструктурировал школьное образование, реформируя различные уровни и условия образования. [...]инициировал процесс осуществления реформ, политики и образовательных действий,[...] а не обуздать частный экспансионистский процесс и сброс направлений высшего образования, способствовали прямо противоположному: он расширился и диверсифицированная и диффреренцированная система, прежде всего, через механизмы доступа, академическую организацию и предлагаемые курсы. В этом контексте он создал так называемые последовательные курсы и университетские центры; учредила фригуру университетов, специализирующихся на области знаний; внедрены центры технологического образования; заменить вестибулярный селебулярными процессами; закончили минимальные учебные программы и смягчили учебные программы; 
созданные технологические курсы и высшие учебные заведения, среди прочих поправок (БИТТАР; БИТТАР, 2012, стр. 165).

Кроме того, стоит вновь заразить, что несколько лет спустя политика, принятая в обоих мандатах правительства президента Фернандо Энрике Кардозу, способствовала, главным образом, росту числа учащихся бразильских государственных школ. Эта политика направлена на привлечение большего числа учащихся, начиная с начальной школы и до средней школы. С другой стороны, государство перестало приоритизировать, таким образом, высшее образование, что автоматически приводит к нехватке ресурсов, а также стимулов. Эта негативная ситуация привела к тому, что в результате досрочного выхода на пенсию учителей, а также привело к увеличению числа случаев их перевода в эквивалентный частный сектор. В этой связи правительство приступило к разработке новой редакции Закона о руководящих принципах и базах 1996 года.

\subsection{BETWEEN ACADEMIC ENCYCLOPEDIAS И ОБШИРНЫе INTERNET CONTENT FOR SCIENTIFIC RESEARCH}

Исследования являются обычной практикой в школах с 1960-х годов, с предложением превратить учащихся в участников их образовательного процесса. Однако само по себе исследование не гарантирует критического развития студентов и зависит от педагогической практики, управляемой преподавателем. Гарсия (2017) утверждает, что процесс исследования был облегчен в геометрической прогрессии после одомашнивания микрокомпьютеров и интернета. Но это означало некоторые нарушения для науки и школьно-академической среды: отбрасываемость информации. Много информации не всегда является синонимом много знаний. Поскольку информация может быть достигнута в несколько кликов, интерес к обучению снизился. До тех пор, осуществление делать школьную работу требует гораздо больше усилий, так как студент должен посвятить несколько часов в библиотеке, глядя в многочисленных книгах для информации, желаемой.

Disponível em: https://www.nucleodoconhecimento.com.br/образование-ru/история- 
Для облегчения этого процесса существовали энциклопедии, в которые изменялись различные темы, а затем продавались выпусками в газетных киосках. В настоящее время Интернет является крупнейшим источником данных для школьных исследований. Это началось с коммерциализации микрокомпьютеров в домашних условиях, которые вскоре были доступны для сети (FERRARESI et al, 2009). До тех пор университеты и школьные учреждения поддерживали культуру поощрения исследований к тому, что было доступно в книгах, энциклопедиях, научных статьях и т.д. По сей день учителям трудно адаптировать свою работу к современным технологическим ресурсам, поскольку Интернет является постоянно расширяющейся и трансформирующейся средой. Поскольку число кибер-пользователей растет в геометрической прогрессии по всей планете и учитывая, что все они пользуются легкостью производства и извлечения контента из сети, используя Интернет в качестве источника исследований для академической работы требует много Уход.

Стоит отметить, что само по себе было создано, во-первых, для академических целей. Научно-научной среды заботится о степени достоверности с учетом информации, полученной из сети. В связи с предлагаемой непосредственностью, связанной с новой культурой электронного мгновенного общения, процент студентов и исследователей, которые до сих пор используют библиотечные книги, печатные статьи и тому подобное для написания своих диссертаций, минимален. В любом случае, университеты, как правило, придерживаются решимости поддерживать свои библиотеки в актуальном состоянии. Интернет не изменил доверие к книгам, поэтому они по-прежнему наиболее высоко ценится в поиске информации. Ferraresi et al (2009, стр. 4) утверждает, что:

Изучение и поиск деятельности через онлайн-коммуникации осуществляются с поисковых сайтов, с преобладанием поискового сайта Google (...). И среди сайтов, которые интервьюируемые знают (...) universiabrasil, ibge и schoolar.google более цитируется. 
В этот новый момент, Рамос и Copolla (2009) суммировать, что академическая среда должна жить до технологического века, адаптируя их внутренней среде к этой реальности. Интернет может быть использован для различных целей и стажеры должны быть обучены для получения краткой и достоверной информации от него, учитывая его хрупкость, так как любой пользователь может производить контент. Это должно быть сделано анализ работы для того, чтобы проверить Интернет, как или нет, это педагогический инструмент, в соответствии с целями пользователя в данный момент времени. Они заявляют, что Интернет в пределах досягаемости домашнего пользователя позволяет сломать классные барьеры и сократить расстояния между учителем и студентом, если он не может или не хочет зависеть от фриксированного графика, и, таким образом, образование приносит пользу коллектива.

(...) Интернет (...) стал потенциально бесконечным источником информации и принес учителям различные виды преимуществ и новые проблемы, потому что, позволяя гораздо более сложные и еще более интересные педагогические вмешательства что традиционные классы (...), привести учителя к лицу изменения в отношениях власти над знанием: где учитель перестает иметь контроль над справочным содержанием и, начинает управлять непредсказуемой информации (...). По этой причине использование этих инструментов в образовании не должно ограничиваться подготовкой учителей в качестве еще одного технологического новшества (РАМОС; КОПОЛЛА, 2009, стр. 7).

Он поощряет способность к самообучению, но не должен приниматься в качестве панацеи, как это было сделано с учебником до этого времени. Это означает, что, как бы технологические ресурсы не вносились в академическую реальность, они не могут быть поняты как единственный возможный инструмент работы для выполнения деятельности, но приводит к динамизму и творчеству, а также устанавливает связь между теоретическими концепциями и личной жизнью каждого из студентов. Интернет является бесконечным источником информации, 
и это приводит к тому, что учитель теряет образ держателя информации. Поэтому необходимо позаботиться о том, чтобы иметь дело с этой инфрормацией.

\subsection{ROLE OF THE TEACHER B METОДОЛОГИЧЕСКИЕ TPAНСФОРМАЦИИ ACADEMIC ENVIRONMENT}

Неоспоримо, что профессия учителя становится гибкой по мере того, как структура всего общества становится в зависимости от его культурных традиций и ресурсов, имеющихся для работы. Человек, в современности, управляет его работой для того, чтобы сделать все слои общества связаны между собой. По этой причине, хороший учитель должен ослабить свою работу в поисках постоянного обновления того, что он может предложить, стремясь к повышению производительности и качества обслуживания, признавая, что включение новых инструментов в реальность классе может принести аспекты Положительные. В этом контексте Рамос и Кополла (2000, стр. 9) ссылаются в своем исследовании на то, что:

Учитель принимает новое отношение. Хотя, раз или снова, он попрежнему играет роль специалиста, который имеет знания и / или опыт общения, чаще всего он будет играть роль советника по деятельности студента, консультант, ведущий обучения тех, кто может сотрудничать для повышения обучения студентов, будет играть роль тех, кто работает в команде, вместе со студентом, стремясь к тем же целям: слово, будет развивать роль педагогического посредничества.

Одной компьютеризации преподавания недостаточно для получения знаний. Учитель, прежде всего, передатчик знаний. Он должен использовать весь свой академический багаж, чтобы привить интерес к студенту для исследования. Известно, что Интернет, при правильном использовании, является источником знаний. Однако при использовании без разбора и без руководства это может

Disponível em: https://www.nucleodoconhecimento.com.br/образование-ru/история- 
представлять собой медвежью услугу информации. Академическая работа, в которой студент использует только всемирную компьютерную сеть в качестве источника исследований для написания своей работы, может привести к безобидной работе. На данный момент мы замечаем важность присутствия учителя, потому что он должен пробудить, в ученике, любопытство, чтобы выйти за рамки простого чтения в Википедии.

Команда фракультета академичной среды сама не одобряет использование некоторых вебсайтов для принятия эссе своих студентов в их научных статьях, в виду того что информация, опубликованная на интернете, будет очень легко быть подделано с, дано легкость, с которой подключенный пользователь также производит содержимое. С другой стороны, этот новый сценарий приносит с собой моменты дисбаланса в его работе, так как студент больше не застрял только на содержание, представленное ему, но также может появиться с вопросами, кроме сюжета класса, на основе содержания доступны в Интернете. Для Рамоса и Кополлы (2000), учитель является агентом, который должен постоянно искать обновления и утилизации своих знаний багажа.

(...) обучение всегда следует учитывать образовательный контекст, в котором учитель вставляется, так что он включает его в его решений известно и обсуждения использования этих технологий необходимо. Позволяя каждому учителю, В рамках своей реальности обучения и действия, сознательно включать эти инструменты и, а не как простой аппарат, чтобы оживить или проиллюстрировать свои классы (RAMOS; КОПОЛЛА, 2000, стр. 12).

Известно, что технологии включают в себя процессы, которые совершенствуются динамически и непрерывно, заставляя их пользователей, и особенно их разработчиков участвовать в том, чтобы идти в ногу с преобразованиями, которые произошли. В академической среде, в целом, не важно, чтобы учителя заботились об архитектуре развития технологических ресурсов, но интересно, что он знает, как совместить эти ресурсы с реальностью

Disponível em: https://www.nucleodoconhecimento.com.br/образование-ru/история- 
класса, так что студенты чувствуют себя погруженными в информационного общества, даже если они находятся в учебно-школьной среде. Погружение урока в виртуальную реальность приносит студентам практическое представление о рассматриваемых темах и делает их более критическими при правильном представлении. Если учитель достигает цели развития творчества, любопытства и взаимодействия у студентов, они будут лучше использовать содержание.

\section{ЗАКЛЮЧИТЕЛЬНЫЕ СООБРАЖЕНИЯ}

Представление в качестве отправной точки истории образования в Бразилии имеет важное значение для разграничивания влияния ее народа в интересах научных исследований. Хотя законодательство, бразильское образование претерпело несколько инвестиций в исследования и образование, так как навсегда, и это связано с политическими интересами. Профрессор Пауло Фрейре даже попытался оставить свой вклад и обратить вспять трагическую картину неграмотности в Бразилии. То же самое было ссылаться на международном уровне и аплодировали великие страны и университеты, но

Здесь проект был разрушен и сильно рецензирован. В XXI веке учитель видит трудности в адаптации к новым тенденциям общества в отношении Интернета, замене библиотек и редакционных статей и снижении доверия к авторству работы, поскольку акт обучения не связан напрямую с технологической вселенной, но это то, что глобализует все слои общества и на работе.

\section{ссылки}

ALVES, W. L. U. A história da educação no Brasil: da Descoberta à Lei de Diretrizes e Bases de 1996. 2009. 76 f. Monografia (Especialização em Metodologia do Ensino Superior) - Centro Universitário Católico Salesiano Auxilium. Lins, 2009.

BITTAR, m; BITTAR, M. História da educação no Brasil: a escola pública no processo de democratização da sociedade. Acta Scientiarum Education, v. 34, n. 2, p. 157168, 2012. 
FERRARESI, A. C. et al. Uso da internet como fonte de pesquisa entre universitários: um estudo de caso. In: XIII Encontro Latino Americano de Iniciação Científica e IX Encontro Latino Americano de Pós-Graduação - Universidade do Vale do Paraíba, 2009

GARCIA, R. Antes do Google e da Wikipédia - as enciclopédias do passado. 2017. Disponível em: https://vejasp.abril.com.br/blog/memoria/antes-do-google-e-dawikipedia/. Acesso em: 17 dez. 2018.

OLIVEIRA, E. S. Diferentes sujeitos e novas abordagens da educação popular urbana. 2001. 152 f. Dissertação (Mestrado em Educação) - Universidade Federal Fluminense. Niterói, 2001.

RAMOS, M; COPOLLa, N. C. O uso do computador e da internet como ferramentas pedagógicas. PDE. 2009. Disponível em: http://www.diaadiaeducacao.pr.gov.br/portals/pde/arquivos/2551-8.pdf. Acesso em: 17 jan. 2019.

RIBEIRO, P. R. M. História da educação escolar no brasil: notas para uma reflexão. Paiadéia, n. 4, p. 15-30, 1993.

ROSA, T. F. lluminismo e a expulsão dos jesuítas do Império Português; as reformas pombalinas e o plano dos estudos menores. Revistas de História Regional, v. 19, n. 2, p. 361-383, 2014.

Представлено: август 2019 года.

Утверждено: декабрь 2019 года. 